Article

\title{
Impurity Antimony-Induced Creep Property Deterioration and Its Suppression by Rare Earth Cerium for a 9Cr-1Mo Ferritic Heat-Resistant Steel
}

\author{
Yewei $\mathrm{Xu}$ and Shenhua Song * \\ Shenzhen Key Laboratory of Advanced Materials, Department of Materials Science and Engineering, \\ Shenzhen Graduate School, Harbin Institute of Technology, Shenzhen 518055, China; xywgk123@sina.com \\ * Correspondence: shsong@hitsz.edu.cn; Tel.: +86-755-2603-3465; Fax: +86-755-2603-3504
}

Academic Editor: Soran Birosca

Received: 9 July 2016; Accepted: 9 August 2016; Published: 12 August 2016

\begin{abstract}
The high temperature creep properties of three groups of modified 9Cr-1Mo steel samples, undoped, doped with $\mathrm{Sb}$, and doped with $\mathrm{Sb}$ and $\mathrm{Ce}$, are evaluated under the applied stresses from $150 \mathrm{MPa}$ to $210 \mathrm{MPa}$ and at the temperatures from 873-923 K. The creep behavior follows the temperature-compensated power law as well as the Monkman-Grant relation. The creep activation energy for the Sb-doped steel $(519 \mathrm{~kJ} / \mathrm{mol})$ is apparently lower than that for the undoped one $(541 \mathrm{~kJ} / \mathrm{mol})$, but it is considerably higher for the $\mathrm{Sb}+\mathrm{Ce}$-doped steel $(621 \mathrm{~kJ} / \mathrm{mol})$. Based on the obtained relations, both the creep lifetimes under $50 \mathrm{MPa}, 80 \mathrm{MPa}$, and $100 \mathrm{MPa}$ in the range $853-923 \mathrm{~K}$ and the $10^{5} \mathrm{~h}$ creep rupture strengths at $853 \mathrm{~K}, 873 \mathrm{~K}$, and $893 \mathrm{~K}$ are predicted. It is demonstrated that the creep properties of the $\mathrm{Sb}$-doped steel are considerably deteriorated but those of the $\mathrm{Sb}+\mathrm{Ce}$-doped steel are significantly improved as compared with the undoped steel. Microstructural and microchemical characterizations indicate that the minor addition of Ce can stabilize the microstructure of the steel by segregating to grain boundaries and dislocations, thereby offsetting the deleterious effect of $\mathrm{Sb}$ by coarsening the microstructure and weakening the grain boundary.
\end{abstract}

Keywords: heat-resistant steels; creep properties; impurities; rare earths; grain boundaries; segregation

\section{Introduction}

In recent years, the problems of energy consumption and environmental pollution require advanced power plants with high efficient utilization of fossil energy, which prompts the development of materials for power plants with higher steam temperature and operating pressure. The modified 9Cr-1Mo ferritic heat-resistant steel, i.e., P91 steel, is extensively employed in the power generation and nuclear energy industries owing to its outstanding high temperature mechanical properties that enable higher operating temperatures and pressures to enhance the thermal efficiency [1-3]. Consequently, it is of great significance to explore the creep properties of this steel.

There have been a number of studies concerning the creep properties of the $9 \mathrm{Cr}$ steel, most of which focus on the evolution of martensitic microstructures including coarsening of precipitates, decreasing in dislocation density, and growing of martensite lath subgrains. Abe et al. [4] investigated the microstructural instability and its effect on the creep behavior of $9 \mathrm{Cr}-2 \mathrm{~W}$ steel and observed that the recovery of dislocations, the agglomeration of carbides, and the growth of martensite lath subgrains occurred during creep with the aid of stress. Spigarelli et al. [5] also found that both large precipitates mainly present on the subgrain boundaries and fine ones mainly present in the subgrain interiors coarsened during creep. Other researchers further found that the creep rupture strength of the high $\mathrm{Cr}$ ferritic steel decreased due to the coarsening of precipitates during creep. After a long-term creep 
process, a new phase, such as Z-phase, formedat the cost of fine precipitates (MX-type carbides) [6,7]. However, there have been few reports concerning the effect of impurity elements or rare earths on the creep properties of P91 steel. Theoretical calculations indicate that the grain boundary cohesion can be increased by the grain boundary segregation of rare earth elements in iron [8,9], while it can be decreased by the grain boundary segregation of impurity elements, such as tin, phosphorus, and antimony in iron [10]. Our previous studies [11,12] regarding the effects of impurity tin and rare earth cerium on the creep properties of P91 heat-resistant steel demonstrated that tin can significantly deteriorate the creep properties of the steel as it can promote the nucleation of cavities or microcracks by grain or subgrain boundary segregation which weakens the boundary cohesion [11]. However, it is indicated that rare earth cerium can evidently improve the creep properties of the steel due to its segregation to grain or subgrain boundaries [12]. Until the present time, the combined effect of impurity elements and rare earths on the creep properties of P91 steel is little reported.

In the present work, we conducted high-temperature creep tests on the P91 steel samples of three groups: undoped, doped with impurity antimony, and doped with both impurity antimony and rare earth cerium. According to the creep rupture data which were extracted from the creep tests, parameters in the temperature-compensated power law [13] and Monkman-Grant relation [14] were determined. With the two relations above, the creep lifetimes of the steel were predicted at several combinations of stress and temperature within the valid range. After that, microstructural and microchemical observations were carried out so as to explore the effect of impurity antimony and the combined effect of impurity antimony and rare earth cerium on the creep properties of the steel.

\section{Materials and Methods}

Three heats of P91 steel: undoped, doped with impurity antimony, and doped with both impurity antimony and rare earth cerium, were prepared by vacuum induction melting with $50 \mathrm{~kg}$ ingots. The chemical compositions of the steels are listed in Table 1 . The ingots were homogenized at $1523 \mathrm{~K}$ and then hot rolled in the range of 1273-1373 K into a plate $18 \mathrm{~mm}$ in thickness. After being austenitized at $1328 \mathrm{~K}$ for $1 \mathrm{~h}$, the steels were air cooled to room temperature, and then tempered at $1033 \mathrm{~K}$ for $3 \mathrm{~h}$, followed by water cooling to create a tempered martensite microstructure.

Table 1. Chemical compositions of undoped, Sb-doped, and Sb+Ce-doped steels (wt. \%).

\begin{tabular}{ccccccccccccccc}
\hline Elt. & $\mathbf{C}$ & $\mathbf{S i}$ & $\mathbf{M n}$ & $\mathbf{S b}$ & $\mathbf{C e}$ & $\mathbf{S}$ & $\mathbf{P}$ & $\mathbf{C r}$ & $\mathbf{M o}$ & $\mathbf{N}$ & $\mathbf{N b}$ & $\mathbf{N i}$ & $\mathbf{V}$ & $\mathbf{F e}$ \\
\hline 1 & 0.12 & 0.30 & 0.46 & - & - & 0.015 & 0.011 & 8.85 & 1.03 & 0.024 & 0.075 & 0.15 & 0.23 & Bal. \\
2 & 0.12 & 0.31 & 0.47 & 0.048 & - & 0.013 & 0.012 & 8.95 & 0.99 & 0.022 & 0.071 & 0.12 & 0.22 & Bal. \\
3 & 0.12 & 0.34 & 0.46 & 0.051 & 0.055 & 0.011 & 0.010 & 9.15 & 0.97 & 0.027 & 0.088 & 0.16 & 0.23 & Bal. \\
\hline \multicolumn{1}{c}{ Note: 1: undoped; 2: Sb-doped; 3: Sb+Ce-doped. } & & &
\end{tabular}

Creep tests were conducted with a high temperature creep testing machine. Since the P91 steel is usually used below $923 \mathrm{~K}$ in engineering [15] and the time to rupture is very long if the testing temperature is below $873 \mathrm{~K}$, the creep tests were conducted between $873 \mathrm{~K}$ and $923 \mathrm{~K}$. The circular creep specimens with a gage length of $50 \mathrm{~mm}$ and a gage diameter of $10 \mathrm{~mm}$ were divided into two groups. For one group, the specimens were creep tested at a constant engineering stress of $150 \mathrm{MPa}$ at $873 \mathrm{~K}$, $885 \mathrm{~K}, 898 \mathrm{~K}, 910 \mathrm{~K}$ and $923 \mathrm{~K}$, respectively, so as to obtain the apparent activation energy $\left(Q_{\mathrm{c}}\right)$ for creep in the temperature-compensated power law. For the other group, the tests were conducted at a constant temperature of $873 \mathrm{~K}$ under the engineering stresses of $210 \mathrm{MPa}, 195 \mathrm{MPa}, 180 \mathrm{MPa}, 165 \mathrm{MPa}$, and $150 \mathrm{MPa}$, respectively, so as to obtain the creep stress exponent $(n)$ in the temperature-compensated power law. At each condition, two specimens were used except testing at a low temperature or stress where one specimen was only employed because the time to rupture was too long.

After creep rupture, to examine the evolution of microstructures and the compositional features at grain or subgrain boundaries, field emission gun scanning transmission electron microscopy equipped with energy dispersive X-ray spectroscopy (FEGSTEM-EDS) was employed. The instrument used in 
the present work was JEM-2100F FEGSTEM (JEOL, Tokyo, Japan) equipped with an Oxford INCA energy dispersive X-ray spectrometer (Oxford Instruments, Oxford, UK), operating under a voltage of $200 \mathrm{kV}$. The disc specimens for FEGSTEM microanalysis were cut from the specimens near the fracture tip as-tempered and creep-tested at $873 \mathrm{~K}$ under $150 \mathrm{MPa}$. More details on FEGSTEM grain boundary microanalysis can be seen in $[16,17]$. In addition, the morphology of the specimens near the fracture tip was observed using optical microscopy.

\section{Results and Discussion}

After creep tests, creep data, such as minimum creep rate $\left(\dot{\varepsilon}_{\mathrm{m}}\right)$ and rupture time $\left(t_{\mathrm{r}}\right)$, for all three groups of P91 steel specimens were extracted from the creep curves, which are listed in Table A1 (see Appendix A). Based on these data, $\ln$ (minimum creep rate) is plotted as a function of reciprocal temperature $(1 / T)$ and $\ln ($ stress), as shown in Figure 1a,b, respectively. Clearly, there is a linear relationship between $\ln$ (minimum creep rate) and reciprocal temperature with $R$-squared values of $0.977,0.997$, and 0.991 (see Figure 1a) or between $\ln$ (minimum creep rate) and $\ln$ (stress) with $R$-squared values of 0.976, 0.994, and 0.998 (see Figure 1b) for the undoped, Sb-doped, and Sb+Ce-doped steels, respectively. As can be seen, the fitted line for the undoped steel is located under those for the $\mathrm{Sb}$-doped and $\mathrm{Sb}+\mathrm{Ce}$-doped steels, showing a better creep behavior. The fitted lines for the Sb-doped and $\mathrm{Sb}+\mathrm{Ce}$-doped steels intersect at a certain temperature, indicating that they have different slopes, i.e., different creep activation energy $\left(Q_{c}\right)$ and stress exponent $(n)$ values. Since the lines for the $\mathrm{Sb}+\mathrm{Ce}$-doped steel are steeper than those for the $\mathrm{Sb}$-doped one, the former has higher $Q_{\mathrm{c}}$ and $n$ values.

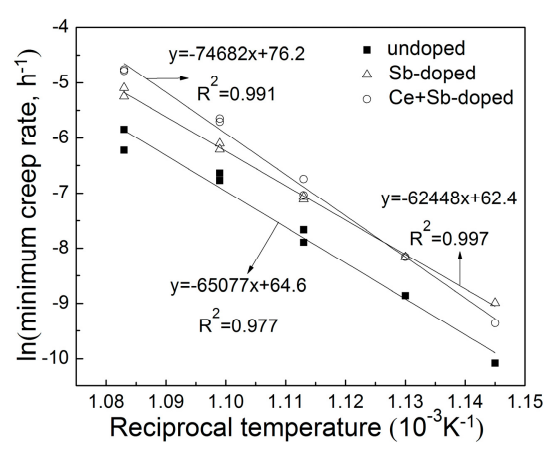

(a)

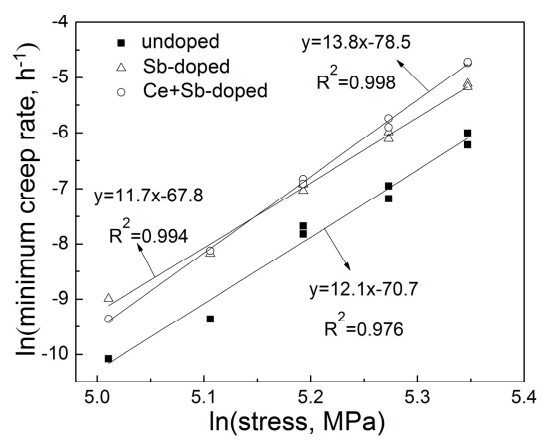

(b)

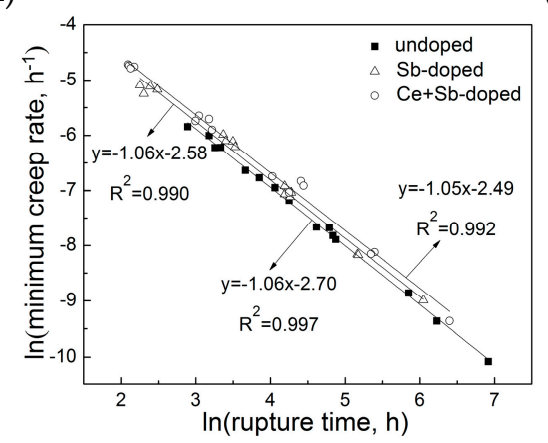

(c)

Figure 1. Variation of minimum creep rate with: (a) reciprocal temperature under a stress of $150 \mathrm{MPa}$; (b) stress at a temperature of $873 \mathrm{~K}$; and (c) rupture time for the undoped, Sb-doped, and $\mathrm{Sb}+\mathrm{Ce}-$ doped steels.

For the undoped steel, the linear fitting gives:

$$
\begin{aligned}
\ln \dot{\varepsilon}_{\mathrm{m}}=-65077 / T+64.6 & (\sigma=150 \mathrm{MPa}) \\
\ln \dot{\varepsilon}_{\mathrm{m}}=12.2 \ln \sigma-70.7 & (T=873 \mathrm{~K})
\end{aligned}
$$


Experimentally, it is frequently observed that, during the steady-state creep, the strain rate or the minimum creep rate $\left(\dot{\varepsilon}_{\mathrm{m}}\right)$ depends on the applied stress $(\sigma)$ and exponentially on the absolute temperature $(T)$ in the form of the temperature-compensated power law [13]:

$$
\dot{\varepsilon}_{\mathrm{m}}=A \sigma^{n} \exp \left(-Q_{c} / R T\right)
$$

where $A$ is a constant, $n$ is the stress exponent for creep, $R$ is the gas constant $(8.314 \mathrm{~J} / \mathrm{mol} \mathrm{K})$, and $Q_{\mathrm{c}}$ is the apparent activation energy for creep. These values are frequently used to estimate the creep properties of steel. The temperature-compensated power law can be rewritten as:

$$
\ln \dot{\varepsilon}_{\mathrm{m}}=\ln A+n \ln \sigma-Q_{c} / \mathrm{RT}
$$

Comparing Equation (4) with Equations (1) and (2), one can obtain $Q_{\mathrm{c}}=541(\mathrm{~kJ} / \mathrm{mol}), n=12.1$ and:

$$
\begin{gathered}
\ln A+n \ln 150=64.6 \\
\ln A-Q_{c} / 7258=-70.7
\end{gathered}
$$

with Equations (5) and (6), the two values of $A$ may be acquired as $A_{1}=61.2 \mathrm{~h}^{-1}$ and $A_{2}=48.2 \mathrm{~h}^{-1}$. Evidently, these two values are roughly close to each other, implying that there is a fixed value of $A$ in the temperature and stress ranges considered. Hence, the mean value of the two values may be taken as the measured one, i.e., $A=54.7 \mathrm{~h}^{-1}$. Similarly, for the $\mathrm{Sb}$-doped steel and $\mathrm{Sb}+\mathrm{Ce}$-doped steel, one can obtain $Q_{\mathrm{c}}=519(\mathrm{~kJ} / \mathrm{mol}), n=11.7$ and $A=42.7\left(\mathrm{Sb}\right.$-doped steel), and $Q_{\mathrm{c}}=621(\mathrm{~kJ} / \mathrm{mol}), n=13.8$ and $A=1152.3$ ( $\mathrm{Sb}+\mathrm{Ce}$-doped steel). Thus, the temperature-compensated power law of creep for the steel may be expressed as:

$$
\begin{array}{cc}
\dot{\varepsilon}_{\mathrm{m}}=54.7 \sigma^{12.1} \exp (-541050 / R T) & (\text { undoped steel }) \\
\dot{\varepsilon}_{\mathrm{m}}=42.7 \sigma^{11.7} \exp (-519192 / R T) & (\text { Sb-doped steel }) \\
\dot{\varepsilon}_{\mathrm{m}}=1152.3 \sigma^{13.8} \exp (-620906 / R T) & (\text { Sb+Ce-doped steel })
\end{array}
$$

where $\dot{\varepsilon}_{\mathrm{m}}$ is in $\mathrm{h}^{-1}, \sigma$ is in $\mathrm{MPa}$, and $T$ is the absolute temperature.

As shown in Equations (7)-(9), the obtained values of stress exponent ( $n=12.1, n=11.7$ and $n=13.8$ for the undoped, Sb-doped, and $\mathrm{Sb}+\mathrm{Ce}$-doped steels, respectively) indicate that all steels deform by the dislocation creep mechanism $[18,19]$. The acquired values of apparent activation energy $\left(Q_{\mathrm{c}}=541 \mathrm{~kJ} / \mathrm{mol}, Q_{\mathrm{c}}=519 \mathrm{~kJ} / \mathrm{mol}\right.$ and $Q_{\mathrm{c}}=621 \mathrm{~kJ} / \mathrm{mol}$ for the undoped, Sb-doped, and Sb+Ce-doped steels, respectively) are apparently higher than the activation energy for self-diffusion in iron (close to $240 \mathrm{~kJ} / \mathrm{mol}$ ), which also indicates a dislocation creep mechanism. In addition, the value of $Q_{\mathrm{c}}$ for the undoped steel is apparently higher than that for the Sb-doped one while the values of $A$ and $n$ are close to each other, indicating that at the same temperature and engineering stress the minimum creep rate of the Sb-doped steel is much higher than that of the undoped one. As for the $\mathrm{Sb}+\mathrm{Ce}$-doped steel, although the values of $A$ and $n$ are higher than those of the other two steels, the value of $Q_{\mathrm{c}}$ is much higher. This means that, at relatively low temperature and engineering stress where the creep process is mainly dominated by the value of $Q_{c}$, the minimum creep rate of the $\mathrm{Sb}+\mathrm{Ce}$-doped steel is much lower than that of the other two steels. The changes of stress exponent $n$ and apparent activation energy $Q_{\mathrm{c}}$ in the three steels indicate that the minor additions of $\mathrm{Sb}$ and Ce significantly affect the creep process of $\mathrm{P} 91$ steel.

As is well known [20], the selection of a material employed at high temperatures needs to take its creep properties into account in engineering design. The creep lifetime of the material under a certain engineering stress or the creep rupture strength of $10^{5} \mathrm{~h}$ creep lifetime is usually used as a reference. 
To estimate the above creep properties of the steel we need to further consider the Monkman-Grant relation, an empirical equation that links the minimum creep rate to the rupture time, which is given by:

$$
\dot{\varepsilon}_{\mathrm{m}} \times t_{\mathrm{r}}^{m}=C
$$

where $\dot{\varepsilon}_{\mathrm{m}}$ is the minimum creep rate, $t_{\mathrm{r}}$ is the rupture time, and $m$ and $C$ are constants. According to the data in Table A1, $\ln$ (minimum creep rate, $\dot{\varepsilon}_{\mathrm{m}}$ ) is plotted as a function of $\ln$ (rupture, $t_{\mathrm{r}}$ ) for the three steels in Figure 1c, demonstrating a sound linear relationship with $R$-square values of 0.997, 0.990; and 0.992, respectively. The linear fitting gives:

$$
\begin{array}{rc}
\ln \dot{\varepsilon}_{\mathrm{m}}=-1.06 \ln t_{r}-2.70 & (\text { undoped steel) } \\
\ln \dot{\varepsilon}_{\mathrm{m}}=-1.06 \ln t_{r}-2.58 & (\text { Sb-doped steel }) \\
\ln \dot{\varepsilon}_{\mathrm{m}}=-1.05 \ln t_{r}-2.49 \quad(\mathrm{Sb}+\mathrm{Ce} \text {-doped steel })
\end{array}
$$

Equation (10) can be rewritten as:

$$
\ln \dot{\varepsilon}_{\mathrm{m}}=-m \ln t_{r}+\ln C
$$

with Equations (11)-(14), one can obtain $m=1.06$ and $C=0.067$ for the undoped steel, $m=1.06$ and $C=0.076$ for the Sb-doped steel, and $m=1.05$ and $C=0.083$ for the $\mathrm{Sb}+\mathrm{Ce}$-doped steel. As a consequence, there are:

$$
\begin{array}{cc}
\dot{\varepsilon}_{\mathrm{m}} \times t_{\mathrm{r}}^{1.06}=0.067 & (\text { undoped steel }) \\
\dot{\varepsilon}_{\mathrm{m}} \times t_{\mathrm{r}}^{1.06}=0.076 \quad(\text { Sb-undoped steel }) \\
\dot{\varepsilon}_{\mathrm{m}} \times t_{\mathrm{r}}^{1.05}=0.083 \quad(\text { Sb+Ce-undoped steel })
\end{array}
$$

where $\dot{\varepsilon}_{\mathrm{m}}$ is in $\mathrm{h}^{-1}$ and $t_{\mathrm{r}}$ is in $\mathrm{h}$.

As seen, the values of parameter $m$ or $C$ are very close to each other for the three steels, indicating that impurity $\mathrm{Sb}$ or rare earth $\mathrm{Ce}$ does not influence the Monkman-Grant relation of the material. Using Equations (7)-(9) along with Equations (15)-(17), one can estimate the creep lifetime at any temperature under any stress with the assumption that both the temperature-compensated power law and the Monkman-Grant equations are valid under the temperature and stress conditions considered. Owing to the fact that the P91 steel is usually employed at a temperature below $923 \mathrm{~K}$ and at a stress below $100 \mathrm{MPa}$ in engineering [15], we estimate the $50 \mathrm{MPa}, 80 \mathrm{MPa}$, and $100 \mathrm{MPa}$ stress creep lifetimes at temperatures between $853 \mathrm{~K}$ and $923 \mathrm{~K}$, and the creep rupture strengths of $10^{5} \mathrm{~h}$ creep lifetime at $853 \mathrm{~K}, 873 \mathrm{~K}$, and $893 \mathrm{~K}$, respectively. The estimated results are shown in Figure 2. Obviously, the $100 \mathrm{MPa}$ stress creep lifetime for the Sb-doped steel is much shorter (up to fifty percent shorter) than that for the undoped steel in the range 853-923 K, while the $100 \mathrm{MPa}$ stress creep lifetime for the $\mathrm{Sb}+\mathrm{Ce}$-doped steel is close to that for the undoped steel in the range 893-923 K. However, in the range 853-893 K where the P91 steel is usually employed in engineering, the $100 \mathrm{MPa}$ stress creep lifetime for the $\mathrm{Sb}+\mathrm{Ce}$-doped steel is apparently longer (1.1 to 1.8 times longer) than that for the undoped steel. Similarly, under $80 \mathrm{MPa}$ and $50 \mathrm{MPa}$ which are closer to the service stress of the P91 steel, the creep lifetime for the Sb-doped steel is much shorter (about fifty percent shorter) than that for the undoped-steel (see Figure $2 b, c$ ), indicating that the creep properties of the Sb-doped steel worsen significantly due to the effect of impurity $\mathrm{Sb}$. As for the $\mathrm{Sb}+\mathrm{Ce}$-doped steel under the above condition, the creep lifetime is much longer (about 10 times longer) than that for the undoped steel (see Figure 2b,c), implying that the creep properties of the steel are significantly improved due to the effect of rare earth Ce. The estimates of the creep rupture strength of $10^{5} \mathrm{~h}$ creep lifetime at $853 \mathrm{~K}$, $873 \mathrm{~K}$, and $893 \mathrm{~K}$ also show that the creep rupture strength for the Sb-doped steel is about 7\% lower than that for the undoped steel, but it is about 3\% higher for the Sb+Ce-doped steel (see Figure 2d). 


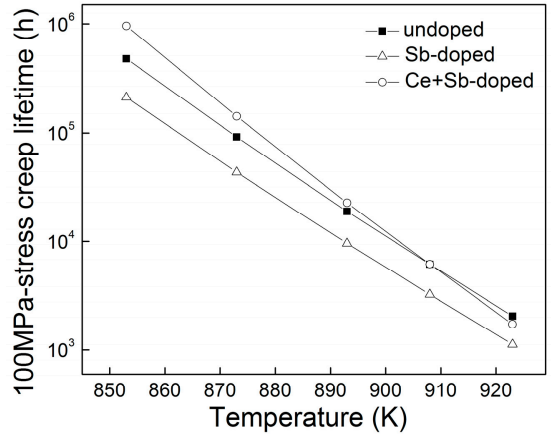

(a)

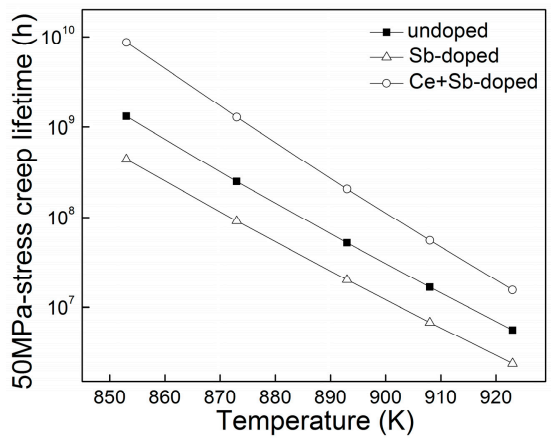

(c)

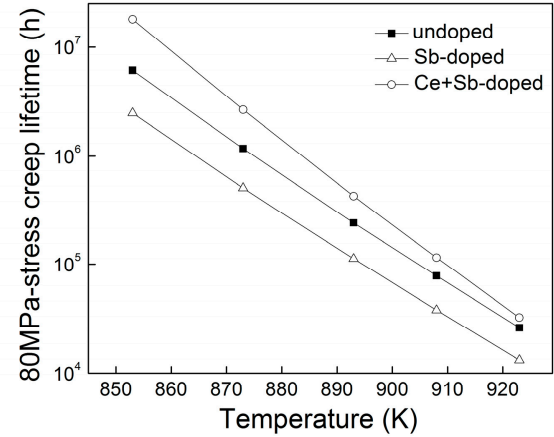

(b)

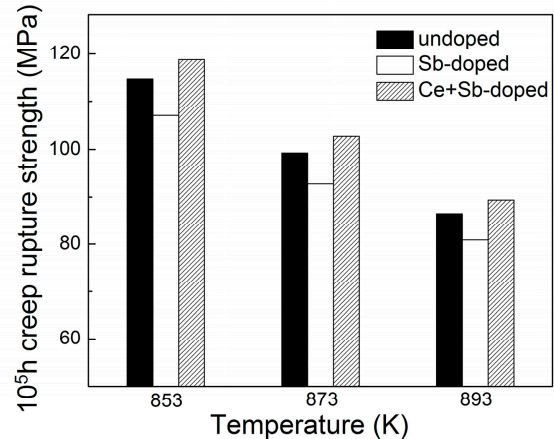

(d)

Figure 2. (a) $100 \mathrm{MPa}$-stess creep lifetime; (b) $80 \mathrm{MPa}$-stess creep lifetime; (c) $50 \mathrm{MPa}$-stess creep lifetime; and (d) $10^{5} \mathrm{~h}$ creep rupture strength of the steels at $853 \mathrm{~K}, 873 \mathrm{~K}$, and $893 \mathrm{~K}$ for the undoped, $\mathrm{Sb}$-doped, and $\mathrm{Sb}+\mathrm{Ce}-$ doped steels.

The evolution of the microstructure of P91 steel plays a crucial role in the creep processes of the material. Normally, during creep, microstructure coarsening, such as precipitate coarsening, dislocation density decrease, and subgrain disappearance, occurs, which deteriorates the creep properties of the steel. In order to explore the effect of impurity $\mathrm{Sb}$ and rare earth $\mathrm{Ce}$ on the microstructure evolution, TEM micrographs were taken from the as-tempered specimens, as well as the specimens crept at $873 \mathrm{~K}$ under $150 \mathrm{MPa}$ for the three steels, which are shown in Figure 3. As seen, the as-tempered specimens (Figure 3a,c,e) exhibit a typical tempered martensite microstructure. The microstructure is with a high density of dislocations and precipitates shown as black dots, which are distributed along prior austenite grain boundaries or martensite lath boundaries. It is indicated by EDS microanalysis that there are two types of precipitates: coarser ones with sizes ranging from $100 \mathrm{~nm}$ to $200 \mathrm{~nm}$, which mainly contain $\mathrm{Cr}$, and finer ones with sizes less than $100 \mathrm{~nm}$, which mainly contain $\mathrm{Nb}$ and $\mathrm{V}$. Accordingly, the coarser precipitates, such as those marked by square in Figure 3, could be $\mathrm{M}_{23} \mathrm{C}_{6}$-type carbides and the finer ones, such as those marked by circle in Figure 3, could be MX-type carbides [6]. The precipitates in the undoped (Figure 3a) and $\mathrm{Sb}+\mathrm{Ce}$-doped steels (Figure 3e) are a little more than those in the Sb-doped steel (Figure 3c) and their dislocation density are somewhat higher. As shown in Figure $3 b, d, f$, the dislocation density is reduced apparently and the precipitates as well as the martensite laths are coarsened after the creep test. However, there are still some dislocations and subgrains remaining in the undoped and $\mathrm{Sb}+\mathrm{Ce}$-doped steels after the creep test, but there are almost no dislocations or subgrains remaining in the Sb-doped steel. This means that the degradation in microstructure is accelerated due to impurity $\mathrm{Sb}$ in the creep process, while rare earth Ce can stabilize the microstructure, thus significantly offsetting the detrimental effect of impurity $\mathrm{Sb}$. 


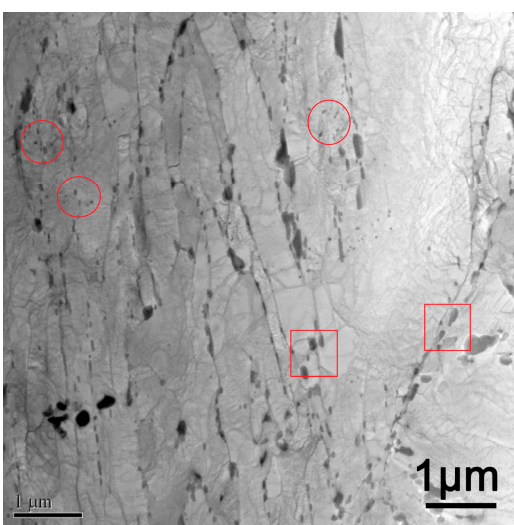

(a)

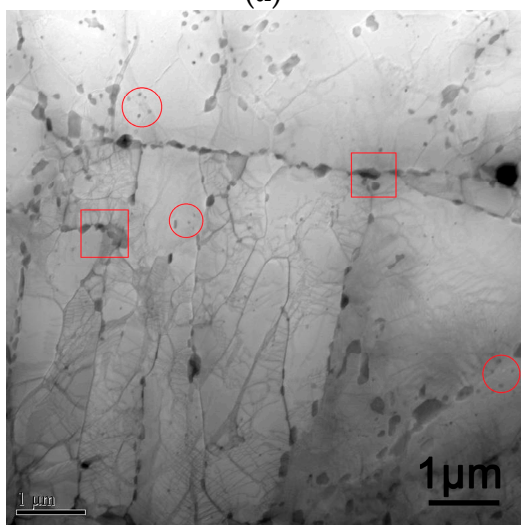

(c)

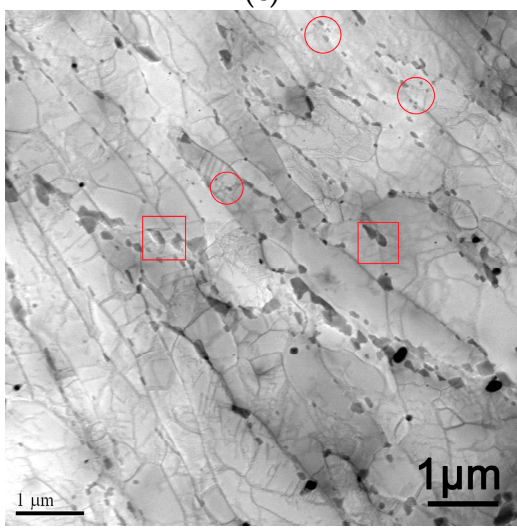

(e)

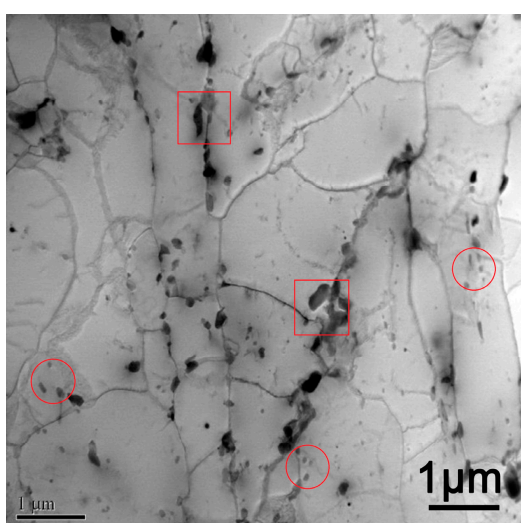

(b)

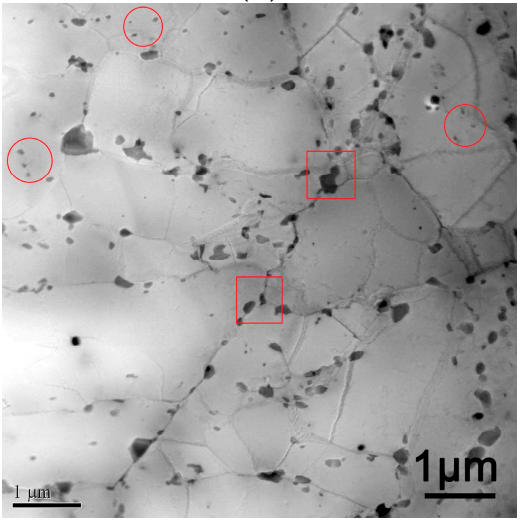

(d)

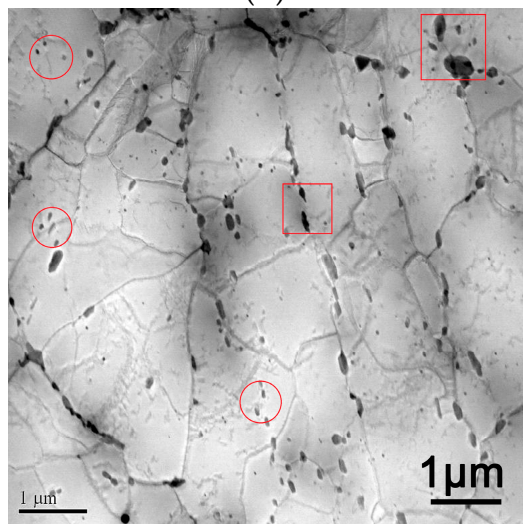

(f)

Figure 3. Transmission electron micrographs of the specimens as-tempered and creep-tested under $150 \mathrm{MPa}$ at $873 \mathrm{~K}$ (the coarser precipitates, such as those marked by a square, are $\mathrm{M}_{23} \mathrm{C}_{6}$-type, while the finer ones, such as those marked by a circle are MX-type): (a) undoped steel as tempered; (b) undoped steel after creep test; (c) Sb-doped steel as tempered; (d) Sb-doped steel after creep test; (e) $\mathrm{Sb}+\mathrm{Ce}$-dopedsteel as tempered; and (f) $\mathrm{Sb}+\mathrm{Ce}$-doped steel after creep test.

Creep rupture is also related to the voids that nucleate, grow and cluster during creep. Study by Otto et al. [21] indicates that the small addition of impurity elements significantly deteriorates the creep properties in $\mathrm{Cu}-0.008 \mathrm{wt}$. \% Bi and $\mathrm{Cu}-0.092 \mathrm{wt}$ \% \% Sb, which is associated with the promotion of the formation of intergranular creep damage such as cavities and microcracks by Bi and $\mathrm{Sb}$. Therefore, we observed the morphology of voids near the fracture tip for the three kinds of specimens tested at $873 \mathrm{~K}$ under $150 \mathrm{MPa}$, which are shown in Figure 4. As can be seen, the voids in the Sb-doped specimens (see Figure 4b) are much more than those in the undoped (see Figure $4 \mathrm{a}$ ) and $\mathrm{Sb}+\mathrm{Ce}-\mathrm{doped}$ specimens (see Figure 4c) where the void morphology is similar to each other. Accordingly, Sb can 
promote the nucleation of voids while the nucleation of voids is restrained in the $\mathrm{Sb}+\mathrm{Ce}$-doped steel. It may be claimed that the promoted formation of voids in the Sb-doped steel may deteriorate its creep properties and thus accelerate creep rupture while the minor addition of Ce can suppress the effect of $\mathrm{Sb}$, thereby improving the creep properties. In addition, as shown in Figure $4 b$, many voids in the Sb-doped steel have linked together and formed linear cracks parallel to the applied stress. With consideration of the deformation texture of the specimens near the fracture tip where the grains are elongated along the direction of the applied stress unless recrystallization takes place, it can be envisaged that the voids are initiated from the boundaries parallel to the applied stress. This is reasonable because during creep the vacancies migrate from the boundaries perpendicular to the applied stress to those parallel to the applied stress. It may be stated from the aforementioned results that the enhancement of void formation in the Sb-doped specimen may be related to the Sb boundary segregation, while the significant decrease of voids in the $\mathrm{Sb}+\mathrm{Ce}$-doped specimen may be related to the effect of Ce boundary segregation.

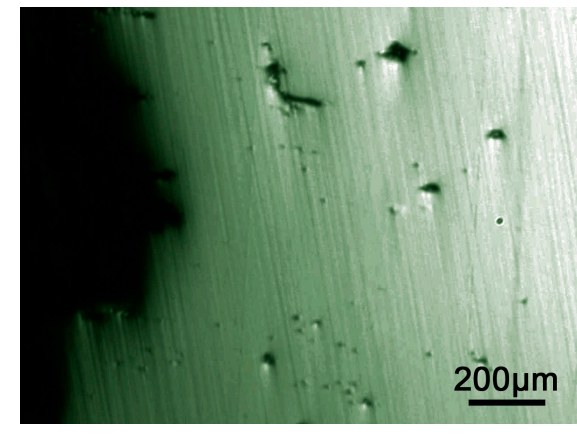

(a)

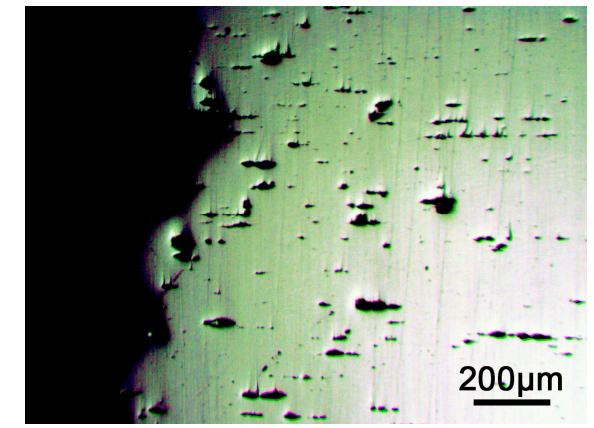

(b)

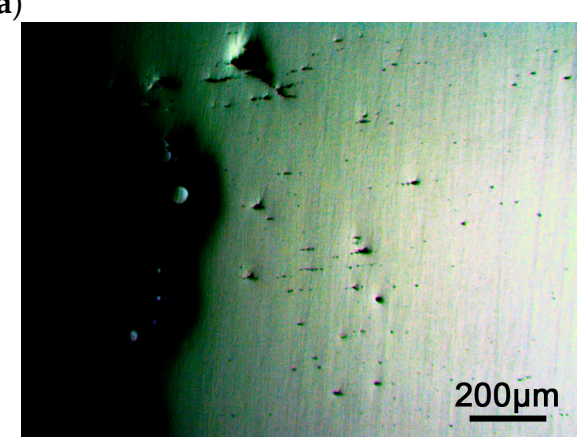

(c)

Figure 4. Morphology of voids near the fracture tip in the specimens tested under $150 \mathrm{MPa}$ at $873 \mathrm{~K}$ : (a) undoped steel ruptured after 1010 h; (b) Sb-doped steel ruptured after 423 h; (c) Sb+Ce-doped steel ruptured after $601 \mathrm{~h}$.

During creep, both impurity element tin and rare earth element cerium can segregate to the grain or subgrain boundaries [22,23]. The equilibrium segregation may occur during isothermal holding prior to creep loading and the non-equilibrium segregation may take place during creep, which is related to a vacancy-solute complex effect or boundary diffusion effect [24,25]. The segregation of impurity element can reduce considerably the grain boundary cohesion in steel, thus promoting the nucleation of cavities on the grain boundaries $[10,21]$ and deteriorating the creep properties of the steel. Nevertheless, the rare earth element can increase the grain boundary cohesion in steel, thus improving the creep properties of the steel. To explore the segregation behavior in the Sb-doped and Sb+Ce-doped specimens, the concentrations of $\mathrm{Sb}$ and $\mathrm{Ce}$ at the boundaries were measured with the use of FEGSTEM after the specimens were tempered and creep-tested at $873 \mathrm{~K}$ under $150 \mathrm{MPa}$. Figure 5 represents an FEGSTEM image showing a segment of grain boundary analyzed, which is free from precipitates. Moreover, the boundary is quite parallel to the incident electron beam, which is suitable for FEGSTEM 
boundary microanalysis. The boundary concentrations of $\mathrm{Sb}$ and $\mathrm{Ce}$ are given in Figure 6 with its matrix concentration plotted for comparison. Obviously, both impurity $\mathrm{Sb}$ and rare earth Ce segregate apparently to the boundaries in the specimens as tempered or creep-tested. The boundary levels of both $\mathrm{Sb}$ and $\mathrm{Ce}$ are over 20 times higher than their matrix levels. The average boundary concentration of $\mathrm{Sb}$ in the $\mathrm{Sb}$-doped specimen increases by approximately $40 \%$ after creep-tested (from 0.47 at. \% to 0.64 at. \%, see Figure $6 \mathrm{a}, \mathrm{c}$ ), while the average boundary concentration of $\mathrm{Sb}$ in the $\mathrm{Sb}+\mathrm{Ce}-\mathrm{doped}$ specimen as tempered ( 0.53 at. \%) is almost the same as that in the $\mathrm{Sb}+\mathrm{Ce}$-doped specimen creep-tested (0.58 at. \%). For clarity, the average boundary concentrations of Sb in the Sb-doped and Sb+Ce-doped specimens as tempered and creep-tested are represented in Figure 7.

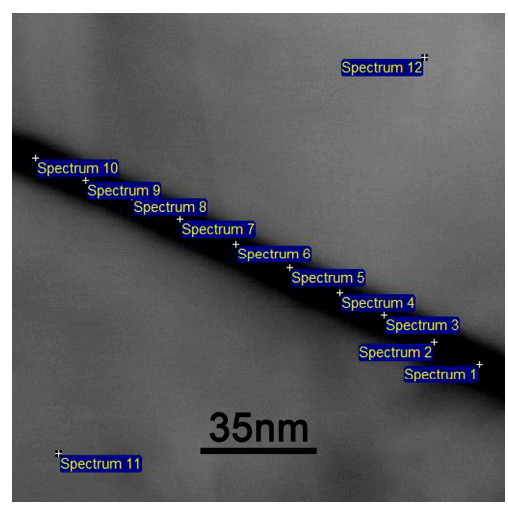

Figure 5. FEGSTEM image showing a segment of grain boundary analyzed.

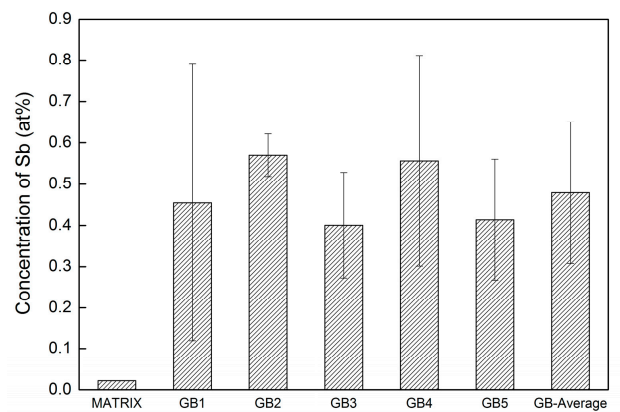

(a)

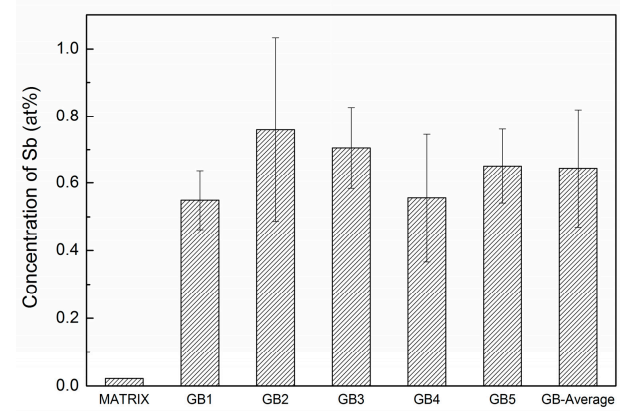

(c)

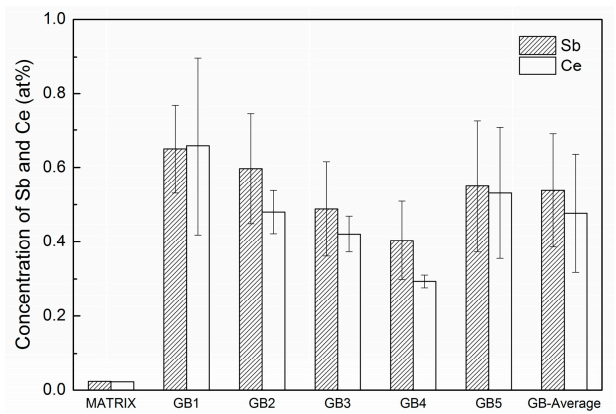

(b)

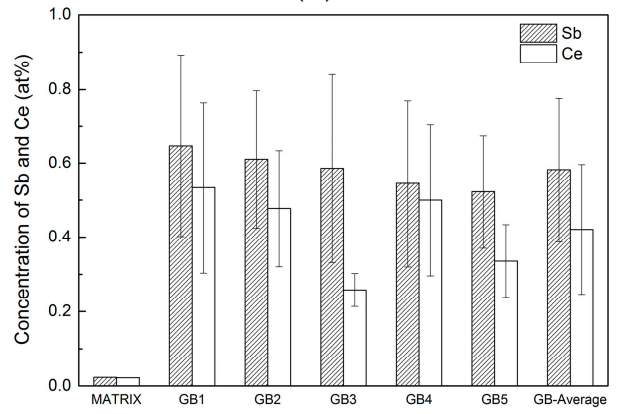

(d)

Figure 6. (a) Grain boundary concentration of $\mathrm{Sb}$ in the Sb-doped specimen as tempered; (b) grain boundary concentrations of $\mathrm{Sb}$ and $\mathrm{Ce}$ in the $\mathrm{Sb}+\mathrm{Ce}$-doped specimen as tempered; (c) grain boundary concentration of $\mathrm{Sb}$ in the $\mathrm{Sb}$-doped specimen creep-tested under $150 \mathrm{MPa}$ at $873 \mathrm{~K}$ (the specimen ruptured after $423 \mathrm{~h}$ ); and (d) grain boundary concentrations of $\mathrm{Sb}$ and $\mathrm{Ce}$ in the $\mathrm{Sb}+\mathrm{Ce}$-doped specimen creep-tested under $150 \mathrm{MPa}$ at $873 \mathrm{~K}$ (the specimen ruptured after $601 \mathrm{~h}$ ), with the matrix concentration plotted for comparison (the error bar represents the standard deviation). 


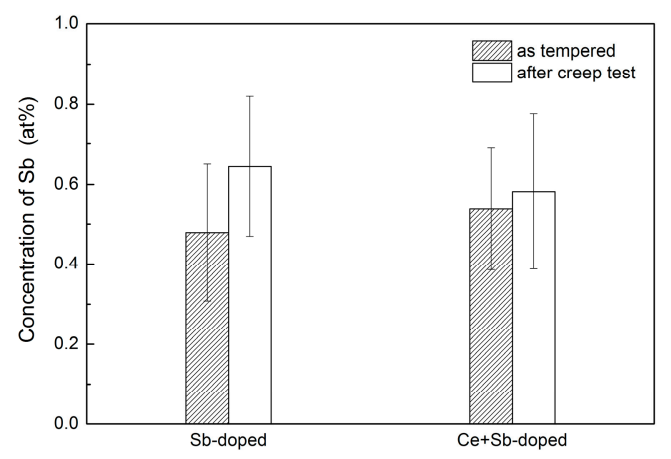

Figure 7. Grain boundary concentrations of $\mathrm{Sb}$ in the $\mathrm{Sb}$-doped and $\mathrm{Sb}+\mathrm{Ce}$-doped specimens as tempered and creep tested (the $\mathrm{Sb}$-doped specimen ruptured after $423 \mathrm{~h}$ and the $\mathrm{Sb}+\mathrm{Ce}$-doped specimen ruptured after $601 \mathrm{~h}$. The error bar represents the standard deviation).

As discussed above, the boundary cohesion can be considerably increased by the boundary segregation of $\mathrm{Ce}$, which can compensate the detrimental effect of $\mathrm{Sb}$ and thereby restrain the initiation of cavities and microcracks. In other words, rare earth Ce can strengthen the boundary in steel. Moreover, rare earth Ce could also segregate to dislocations, which may restrict the slip and climb of the dislocations, thus stabilizing the dislocations and leading to a higher apparent activation energy for creep $(621 \mathrm{~kJ} / \mathrm{mol})$. With these mechanisms, rare earth Ce can stabilize the microstructure of the steel during creep, which may be the reason why there are more dislocations and subgrains remaining in the $\mathrm{Sb}+\mathrm{Ce}$-doped specimen than in the $\mathrm{Sb}$-doped specimen after creep test, and the microstructure in the $\mathrm{Sb}+\mathrm{Ce}$-doped specimen are not apparently coarsened as compared with that in the Sb-doped specimen. In addition, as shown in Figure 7, the rare earth $\mathrm{Ce}$ in the $\mathrm{Sb}+\mathrm{Ce}$-doped steel can reduce the boundary segregation of $\mathrm{Sb}$, thus suppressing the effect of $\mathrm{Sb}$ to a certain degree. Consequently, the creep properties of the $\mathrm{Sb}+\mathrm{Ce}$-doped steel are apparently better than those of the Sb-doped steel.

\section{Conclusions}

The creep properties of three groups of P91 ferritic heat-resistant steel specimens, undoped, doped with antimony, and doped with both antimony and cerium, are examined under the applied stresses from 150-210 MPa and at the temperatures from 873-923 K. The creep behaviors agree with the temperature-compensated power law and Monkman-Grant relation. For the temperature-compensated power law equation, the values of apparent activation energy and stress exponent for creep are about $541 \mathrm{~kJ} / \mathrm{mol}$ and 12.1 for the undoped steel, $519 \mathrm{~kJ} / \mathrm{mol}$, and 11.7 for the Sb-doped steel, and $621 \mathrm{~kJ} / \mathrm{mol}$ and 13.8 for the $\mathrm{Sb}+\mathrm{Ce}$-doped steel, respectively. For the Monkman-Grant equation, the values of constants $m$ and $C$ are around 1.06 and 0.067 for the undoped steel, 1.06 and 0.076 for the Sb-doped steel, and 1.05 and 0.083 for the $\mathrm{Sb}+\mathrm{Ce}$-doped steel, respectively. In terms of these relationships, the creep lifetimes for the three steels are predicted under several conditions. It is demonstrated that minor $\mathrm{Sb}$ can significantly deteriorate the creep properties of the steel, but they can, evidently, be improved by the minor addition of Ce. Rare earth Ce can both strengthen the grain boundary and stabilize the microstructure of the steel by segregating to grain boundaries and dislocations, which leads to a high apparent activation energy for creep $(621 \mathrm{~kJ} / \mathrm{mol})$. This beneficial effect can offset the detrimental effect of $\mathrm{Sb}$ that enhances the coarsening of microstructure and deteriorates the grain boundary by segregation.

Acknowledgments: This work was supported by the National Natural Science Foundation of China (Grant No. 51071060).

Author Contributions: Yewei Xu contributed to experimental work and result analysis. Shenhua Song contributed to research design and result analysis.

Conflicts of Interest: The authors declare no conflict of interest. 


\section{Appendix A}

After creep tests, the values of minimum creep rate and creep rupture time were obtained from the creep curves. These data are listed in Table A1.

Table A1. Minimum creep rate and rupture time for the undoped, Sb-doped, and Sb+Ce-doped specimens tested at various engineering stresses and temperatures.

\begin{tabular}{|c|c|c|c|c|c|c|c|}
\hline \multirow{2}{*}{$\begin{array}{l}\text { Temp. } \\
\text { (K) }\end{array}$} & \multirow{2}{*}{$\begin{array}{l}\text { Stress } \\
(\mathbf{M P a})\end{array}$} & \multicolumn{3}{|c|}{ Creep Rate $\left(h^{-1}\right)$} & \multicolumn{3}{|c|}{ Rupture Time (h) } \\
\hline & & Undoped & Sb-Doped & Sb+Ce-Doped & Undoped & Sb-Doped & Sb+Ce-Doped \\
\hline 923 & 150 (test 1 ) & $1.98 \times 10^{-3}$ & $5.27 \times 10^{-3}$ & $8.37 \times 10^{-3}$ & 26 & 10 & 8.4 \\
\hline 923 & 150 (test 2) & $2.90 \times 10^{-3}$ & $6.13 \times 10^{-3}$ & $8.59 \times 10^{-3}$ & 18 & 9.5 & 8.8 \\
\hline 910 & 150 (test 1$)$ & $1.31 \times 10^{-3}$ & $2.24 \times 10^{-3}$ & $3.52 \times 10^{-3}$ & 39 & 30 & 21 \\
\hline 910 & 150 (test 2) & $1.15 \times 10^{-3}$ & $2.01 \times 10^{-3}$ & $3.33 \times 10^{-3}$ & 47 & 34 & 24 \\
\hline 898 & 150 (test 1$)$ & $3.74 \times 10^{-4}$ & $8.13 \times 10^{-4}$ & $1.18 \times 10^{-3}$ & 131 & 71 & 56 \\
\hline 898 & 150 (test 2) & $4.70 \times 10^{-4}$ & $8.53 \times 10^{-4}$ & $8.77 \times 10^{-4}$ & 101 & 66 & 70 \\
\hline 885 & 150 (test 1 ) & $1.42 \times 10^{-4}$ & $2.86 \times 10^{-4}$ & $2.87 \times 10^{-4}$ & 347 & 175 & 210 \\
\hline 873 & 150 (test 1$)$ & $4.20 \times 10^{-5}$ & $1.25 \times 10^{-4}$ & $8.60 \times 10^{-5}$ & 1010 & 423 & 601 \\
\hline 873 & 165 (test 1 ) & $8.60 \times 10^{-5}$ & $2.82 \times 10^{-4}$ & $2.97 \times 10^{-4}$ & 507 & 177 & 220 \\
\hline 873 & 180 (test 1 ) & $4.02 \times 10^{-4}$ & $8.80 \times 10^{-4}$ & $1.08 \times 10^{-3}$ & 126 & 72 & 82 \\
\hline 873 & 180 (test 2) & $4.64 \times 10^{-4}$ & $9.87 \times 10^{-4}$ & $9.94 \times 10^{-4}$ & 120 & 66 & 85 \\
\hline 873 & 195 (test 1 ) & $9.58 \times 10^{-4}$ & $2.51 \times 10^{-3}$ & $2.74 \times 10^{-3}$ & 58 & 29 & 25 \\
\hline 873 & 195 (test 2) & $7.62 \times 10^{-4}$ & $2.22 \times 10^{-3}$ & $3.21 \times 10^{-3}$ & 70 & 33 & 20 \\
\hline 873 & 210 (test 1$)$ & $2.47 \times 10^{-3}$ & $6.01 \times 10^{-3}$ & $8.77 \times 10^{-3}$ & 24 & 11 & 8.2 \\
\hline 873 & 210 (test 2) & $1.99 \times 10^{-3}$ & $5.67 \times 10^{-3}$ & $8.96 \times 10^{-3}$ & 28 & 12 & 8.1 \\
\hline
\end{tabular}

\section{References}

1. Mannan, S.L.; Chetal, S.C.; Raj, B.; Bhoje, S.B. Selection of materials for prototype fast breeder reactor. Trans. Indian Inst. Met. 2003, 56, 155-178.

2. Klueh, R.L.; Ehrlich, K.; Abe, F.J. Ferritic/Martensitic steels: Promises and problems. Nucl. Mater. 1992, 191, $116-124$.

3. Klueh, R.L. Elevated temperature ferritic and martensitic steels and their application to future nuclear reactors. Int. Mater. Rev. 2005, 50, 287-310. [CrossRef]

4. Abe, F.; Nakazawa, S.; Araki, H.; Node, T. The role of microstructural instability on creep-behavior of a martensitic 9Cr-2W steel. Mater. Trans. A 1992, 23, 469-477. [CrossRef]

5. Spigarelli, S.; Cerri, E.; Bianchi, P.; Evangelista, E. Interpretation of creep behaviour of a $9 \mathrm{Cr}-\mathrm{Mo}-\mathrm{Nb}-\mathrm{V}-\mathrm{N}$ (T91) steel using threshold stress concept. Mater. Sci. Technol. 1999, 15, 1433-1440. [CrossRef]

6. Maruyama, K.; Sawada, K.; Koike, J. Strengthening mechanisms of creep resistant tempered martensitic steel. ISIJ Int. 2001, 41, 641-653. [CrossRef]

7. Hald, J. Microstructure and long-term creep properties of $9 \%-12 \% \mathrm{Cr}$ steels. Int. J. Press. Vessel. Pip. 2008, 85, 30-37. [CrossRef]

8. Liu, G.L.; Zhang, G.Y.; Li, R.D.; Chin, J. Electronic theoretical study of the interaction between rare earth elements and impurities at grain boundaries in steel. J. Rare earths 2003, 21, 372-374.

9. Zhang, D.B.; Wu, C.J.; Yang, R. Interaction between cerium and phosphorus segregating in the grain boundaries in $\alpha$-Fe studied by computer modelling and Auger electron spectroscopy. Mater. Sci. Eng. A 1991, 131, 93-97. [CrossRef]

10. Seah, M.P. Adsorption-induced interface decohesion. Acta Metall. 1980, 28, 955-962. [CrossRef]

11. Song, S.H.; Xu, Y.W.; Yang, H.F. Effect of impurity tin on the creep properties of a P91 heat-resistant steel. Metall. Mater. Trans. A 2014, 45, 4361-4370. [CrossRef]

12. Xu, Y.W.; Song, S.H.; Wang, J.W. Effect of rare earth cerium on the creep properties of modified 9Cr-1Mo heat-resistant steel. Mater. Lett. 2015, 161, 616-619. [CrossRef]

13. Brown, A.M.; Ashby, M.F. On the power-law creep equation. Scr. Mater. 1980, 14, 1297-1302. [CrossRef]

14. Monkman, F.C.; Grant, N.J. An empirical relationship between rupture life and minimum creep rate in creep-rupture tests. Proc. Am. Soc. Test. Mater. 1956, 56, 593-620. 
15. Ennis, P.J.; Czyrska-Filemonowicz, A. Recent advances in creep-resistant steels for power plant applications. Sadhana 2003, 28, 709-730. [CrossRef]

16. Song, S.H.; Weng, L.Q. An FEGSTEM study of grain boundary segregation of phosphorus during quenching in a 2.25Cr-1Mo steel. J. Mater. Sci. Technol. 2005, 21, 445-450.

17. Chen, X.M.; Song, S.H.; Weng, L.Q.; Liu, S.J. Solute grain boundary segregation during high temperature plastic deformation in a Cr-Mo low alloy steel. Mater. Sci. Eng. A 2011, 528, 7663-7668. [CrossRef]

18. Kassner, M.E.; Perez-Prado, M.T. Five-power-law creep in single phase metals and alloys. Prog. Mater. Sci. 2000, 45, 1-102. [CrossRef]

19. Latha, S.; Mathew, M.D.; Parameswaran, P.; BhanuSankaraRao, K.; Mannan, S.L. Thermal creep properties of alloy D9 stainless steel and 316 stainless steel fuel clad tubes. Int. J. Press. Vessel. Pip. 2008, 85, 866-870. [CrossRef]

20. Wang, Y.; Mayer, K.H.; Scholz, A.; Berger, C.; Chilukuru, H.; Durst, K.; Blum, W. Development of new 11\% $\mathrm{Cr}$ heat resistant ferritic steels with enhanced creep resistance for steam power plants with operating steam temperatures up to $650{ }^{\circ} \mathrm{C}$. Mater. Sci. Eng. A 2009, 510, 180-184. [CrossRef]

21. Otto, F.; Viswanathan, G.B.; Payton, E.J.; Frenzel, J.; Eggeler, G. On the effect of grain boundary segregation on creep and creep rupture. Acta Mater. 2012, 60, 2982-2998. [CrossRef]

22. Matsuoka, H.; Osawa, K.; Ono, M.; Ohmura, M. Influence of $\mathrm{Cu}$ and $\mathrm{Sn}$ on hot ductility of steels with various C content. ISIJ Int. 1997, 37, 255-262. [CrossRef]

23. Song, S.H.; Yuan, Z.X.; Jia, J.; Guo, A.M.; Shen, D.D. The role of tin in the hot ductility deterioration of a low-carbon steel. Metall. Meter. Trans. A 2003, 34, 1611-1616. [CrossRef]

24. Song, S.H.; Wu, J.; Yuan, Z.X.; Weng, L.Q.; Xi, T.H. Non-equilibrium grain boundary segregation of phosphorus under a high applied tensile stress in a 2.25Cr1Mo steel. Mater. Sci. Eng. A 2008, 486, 675-679. [CrossRef]

25. Song, S.H.; Wu, J.; Weng, L.Q.; Liu, S.J. Phosphorus grain boundary segregation under different applied tensile stress levels in a Cr-Mo low alloy steel. Mater. Lett. 2010, 64, 849-851. [CrossRef]

(C) 2016 by the authors; licensee MDPI, Basel, Switzerland. This article is an open access article distributed under the terms and conditions of the Creative Commons Attribution (CC-BY) license (http://creativecommons.org/licenses/by/4.0/). 